\title{
Green method for the synthesis of crotonolactone and its thiosulfonate derivatives
}

\author{
Nataliya Monka, Anna Nakonechna, Viktor Zvarych, Volodymyr Novikov, \\ Vira Lubenets
}

Department of Technology of Biologically Active Substances, Pharmacy and Biotechnology, Lviv Polytechnic National University, UKRAINE, Lviv-13, S. Bandera Str. 12.

E-mailvlubenets@gmail.com

\begin{abstract}
Crotonolactone as an important intermediate synthetic product with a broad spectrum of biological effects was synthesized using the concept of green chemistry. An oxidation of furfural was carried out under mild conditions and using non-toxic reagents. The interaction of salts of aromatic thiosulfonic acids with $\gamma$-crotonolactone in an aqueous medium was studied, and new $\gamma$-[4((phenylsulfonyl)thio)]crotonic acids were obtained. The structures of the newly synthesized compounds are confirmed by the data of IR and ${ }^{1} H$ NMR spectroscopy.
\end{abstract}

Keywords - $2(5 \mathrm{H})$-furanone ( $\gamma$-crotonolactone), green chemistry, hydrogen peroxide, acetic acid, thiosulphonates, thiosulfoacid derivatives; thiosulfoesters.

\section{Introduction}

$2(5 H)$-Furanone ( $\gamma$-crotonolactone) and its derivatives are important synthetic products with a wide range of biological effects. The use of these compounds in synthetic organic chemistry and in the national economy is well known [1]. In particular, 2(5H)-furanones are known as antimicrobial compounds. [2]. They are found in beer, kvass, contaminated food, and especially in contaminated feed exposed to mold fungi. [3]. The $\gamma$-crotonolactone derivatives attract considerable attention as plant growth regulators [4], as substances that inhibit the growth of tumors in the human body, since they are inhibitors of cell metamorphosis [5], and promoters of growth of industrial fish cultures [6].

Aromatic thiosulfoesters are structural analogues of phytoncides isolated from garlic and onions, which exhibit a wide spectrum of biological activity, and have high reactivity to nucleophilic reagents. They are effective thiolating and sulfonylating reagents, and it is also possible to use them to stabilize polymers and creatine kinase [7,8]. Thiosulfonic esters have been proposed as effective plant protection products, growth regulators [9], biocidal additives, fruit and vegetable preservatives [10], insecticides [11], radioprotective agents and medicinal substances $[12,13,14]$. Therefore, it is relevant to obtain new thiosulfoesters based on $\gamma$ crotonolactone.

\section{Results and discussion}

We have solved the environmental problem of the method of obtaining $2(5 H)$-furanone $(\gamma-$ crotonolactone), based on the concept of green chemistry. A method for the synthesis of $\gamma$ crotonolactone under mild conditions using non-toxic reagents by the oxidation of furfural with hydrogen peroxide in the presence of acetic acid in a ratio of 1: 0.05 has been developed. As a by-product in this process, a mixture of organic acids (succinic, maleic, fumaric, formic and cinnamic acids) is formed (Scheme 1). The mixture of organic acids can be used as a highly effective, environmentally friendly organic fertilizer or as a drug with a stimulating effect. 


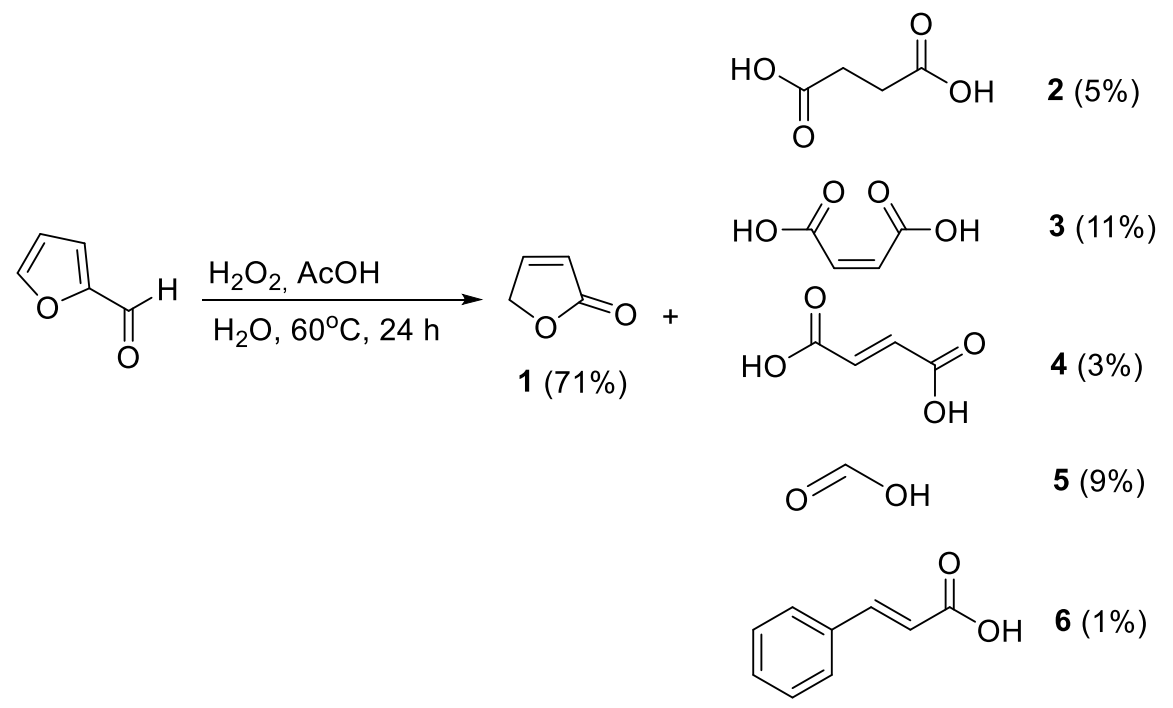

Scheme 1. Oxidation of Furan-2-carbaldehyde

$\gamma$-Crotonolactone has been used to synthesize new biologically active $\gamma$-substituted [4((phenylsulfonyl)thio)]crotonic acids (Scheme 2).

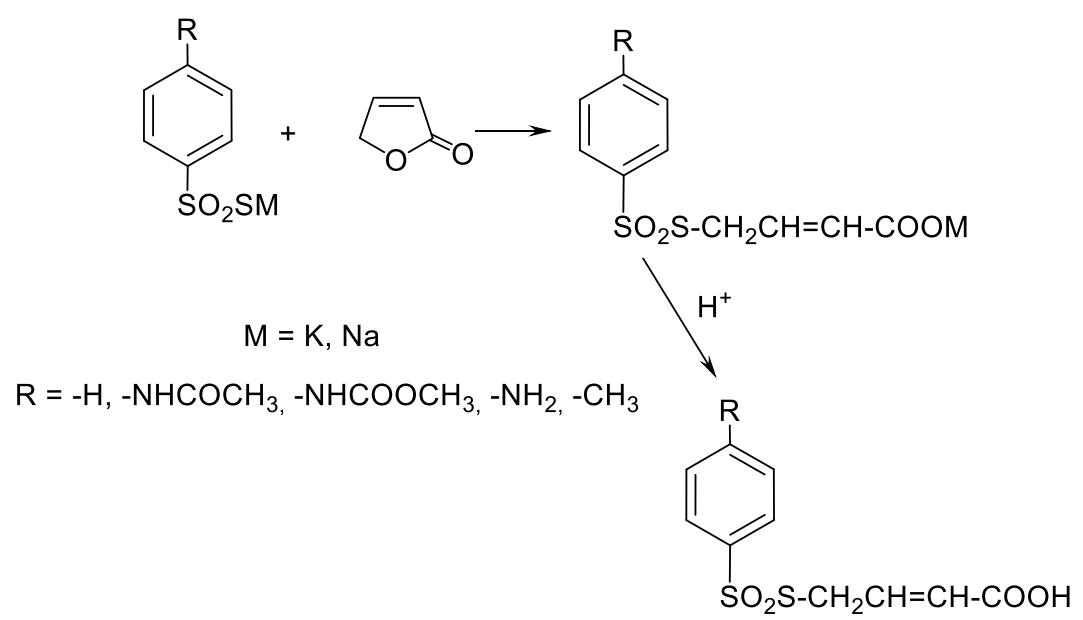

Scheme 1. Alkylation of thiosulfonic acid salts with $\gamma$-crotonolactone

We have found that alkali metal salts of thiosulfonic acids are easily alkylated with $\gamma$ crotonolactone under conditions of the concept of green chemistry in an aqueous medium. The reaction products are salts, which, after cooling the reaction mass, were acidified with diluted hydrochloric acid, and corresponding $\gamma$-substituted [4 - ((phenylsulfonyl) thio)]crotonic acids were obtained (80-90\%). $\mathrm{t}$ has been established that the alkylation of bifunctional salts of 4aminobenzenothiosulfonic acid under the conditions indicated above occurs only on the thiosulfonate group. The structures of the synthesized substances were confirmed by the data of IR, ${ }^{1} \mathrm{H}$ NMR spectroscopy, the composition by the data of elemental analysis, and individuality by data of TLC. 


\section{Conclusion}

A new green chemistry method for the synthesis of $2(5 H)$-furanone ( $\gamma$-crotonolactone) was proposed. New promising biologically active $\gamma$-substituted [4-((phenylsulfonyl)thio)]crotonic acids under conditions of green chemistry were obtained in an aqueous medium with high yields.

\section{References}

[1] R.Rossi, M. Lessi, C. Manzini, G. Marianetti, F. Bellina, Synthesis and biological properties of $2(5 \mathrm{H})$-furanones featuring bromine atoms on the heterocyclic ring and/or brominated substituents. Curr. Org. Chem. Vol. 21, pp.964-1018, 2017.

[2] P. Šenel, L. Tichotova, I. Votruba, V. Buchta, M.'S' ' pulak, J. Kunes, M. Nobilis, O. Krenk, M. Pour. Antifungal 3,5- disubstituted furanones: From 5-acyloxymethyl to 5alkylidenederivatives. Bioorg. Med. Chem. Vol.18, pp.1988-2000, 2010.

[3] C. Scholtes, S. Nizet, S. Collin. How Sotolon Can Impart aMadeira Off-Flavor to Aged Beers. J. Agric. Food Chem. Vol. 63,pp.2886-2892, 2015.

[4] M. E. Light, B. V. Burger, D. Staerk, L. Kohout, J. Van Staden. Butenolides from PlantDerived Smoke: Natural Plant-GrowthRegulators with Antagonistic Actions on Seed Germination. J. Nat.Prod. Vol.73, pp.267-269, 2010.

[5] S. Dobretsov, M. Teplitski, V. Paul. Mini-review: Quorumsensing in the marine environment and its relationship to biofouling.Biofouling Vol.25, pp.413-427, 2009.

[6] V.V. Nemchenko, N. P. Ivanova. Growth regulators for dressingof corn seed. Khim. Sel'sk. Khoz. 1, 91-93, 1991; Chem. Abstr. Vol.115, pp. 44136. 1991.

[7] Pat. 4931392 USA, MKU G12N-009/12. Process for stabilizing kinase -reacting with disulfide or thiosulfonate and carbohydrate / Knut B., Helmut R.,Sibylle R., Peter S., Wilhelm T.; № 355039; Filed: 15.05.89; Pub. Date: 05.06.90 //C.A. DE 3540076 A1.

[8] Pat. 2534936 USA, MKU C08K-005/41. Stabilized vinyl chloride polymers / Henry W.A.; № 43533; Filed:. 10.08.48; Pub. Date: 19.12.50 // C.A. 3652c.

[9] Pat 124324 Ukraine C07C381/04. Zastosuvannia S-etyl-4-aminobenzentiosulfonatu yak rehuliatora rostu ta biotsydu dlia borotby $\mathrm{z}$ fitopatohennoiu mikrofloroiu pry fitorekultyvatsii naftozabrudnenykh gruntiv / V. Lubenets, S. Vasylyuk, A., Nakonechna, V.Shvets, A. Banya, O. Karpenko, V.Novikov.; № u201707007; Filed:. 03.07.2017; Pub. Date: 10.04.2018, Bull. №7, 2018. (in Ukrainian)

[10] V. Lubenets, N. Stadnytska, D. Baranovych, S. Vasylyuk, O. Karpenko, V. Havryliak, V. Novikov. Thiosulfonates: the Prospective Substances against Fungal Infections. IntechOpen, the world's leading publisher of Open Access books. Fungal Infections , pp.1-25, 2019.

[11] E. Santos, F. Gonçalves, P.Prado, D. Sasaki, D. Lima, M.Macedo. Synthesis Method for Thiosulfonate and Report of Its Insecticidal Activity in Anagasta kuehniella (Lepidoptera Pyralidae). Int. J. Mol. Sci. Vol. 13. P. 15241-15251, 2012.

[12] Pat. 2573077 France, MKU C 07 D 235/28; A 61 K 31/47. Nouveaux derivesthiosulfonates, leur procede de preparation ainsi que les compositionspharmaceutiques les contenant / Sebille Bernard, Beuzard Yves, Demarne Henri. - №8417286; Filed:. 13.11.84; Pub. Date: 16.05.86

[13] V.I. Lubenets. Tiosulfonaty: syntezi vlastyvosti. Ukrainskii Khimicheskii Zhurnal. Vol.69.№ 3. pp.109-117, 2003. (in Ukrainian)

[14] N.Ya. Monka, S.V. Vasylyuk, A.V. Nakonechna, Kh. B. Bolibrukh, V. I. Lubenets Esters of thiosulfoacids: obtaining, properties and application perspectives. Ukrainskii Khimicheskii Zhurnal. Vol.84.№10.pp.1-33, 2018. (in Ukrainian) 